\title{
Author Correction: Amine hemilability enables boron to mechanistically resemble either hydride or proton
}

C. Frank Lee, Diego B. Diaz D , Aleksandra Holownia, Sherif J. Kaldas, Sean K. Liew, Graham E. Garrett (D), Travis Dudding and Andrei K. Yudin (iD

Correction to: Nature Chemistry https://doi.org/10.1038/s41557-018-0097-5 (2018), published online 30 July 2018.

During the revision of this Article prior to publication, a computational study was reported (Vallejos, M. M. \& Pellegrinet, S. C. Theoretical study of the $\mathrm{BF}_{3}$-promoted rearrangement of oxiranyl $\mathrm{N}$-methyliminodiacetic acid boronates. J. Org. Chem. 82, 5917-5925; 2017) that evaluates the nucleophilic boryl transfer mechanism predicted in this Article; this reference has now been added as number 19 , and the subsequent references renumbered. 